\title{
THE IMPLEMENTATION OF PHBS IN EARLY CHILDREN'S EDUCATION (PAUD) THROUGH HOW TO WASH YOUR HANDS WITH SOAP Correctly
}

\author{
Rina Yulviana, Sri Mayang, Resti Utari
}

\author{
abstract
}

The World Health Organization (WHO) has launched the concept of a healthy school (Health Promoting School), which is a school that has implemented UKS (School Health Enterprises) with the characteristics of involving all parties related to school health problems, creating a healthy and safe environment, providing health education, there are school policies and efforts to promote health and play an active role in improving public health.

School children are the nation's next generation whose health needs to be maintained, improved and protected. Some activities of students in implementing PHBS in schools include washing hands with soap and clean water by implementing PHBS in schools so that students take an active role in creating a healthy school environment.

Key Words: Hand Wash, PHBS

\begin{abstract}
Abstrak
Organisasi Kesehatan Dunia (WHO) telah mencanangkan konsep sekolah sehat (Health Promoting School), adalah sekolah yang telah melaksanakan UKS (Usaha Kesehatan Sekolah) dengan ciri-ciri melibatkan semua pihak yang berkitan dengan masalah kesehatan sekolah, menciptakan lingkungan yang sehat dan aman, memberikan pendidikan kesehatan, ada kebijakan dan upaya sekolah untuk mempromosikan kesehatan dan berperan aktif dalam meningkatkan kesehatan masyarakat.

Anak sekolah merupakan generasi penerus bangsa yang perlu dijaga, ditingkatkan dan dilindungi kesehatannya. Beberapa kegiatan peserta didik dalam menerapkan PHBS di sekolah antara lain mencuci tangan dengan sabun dan air bersih dengan menerapkan PHBS di sekolah maka peserta didik ikut berperan aktif dalam mewujudkan lingkungan sekolah yang sehat.
\end{abstract}

Kata Kunci : Cuci Tangan, PHBS

\section{PENDAHULUAN}

Organisasi Kesehatan Dunia (WHO) telah mencanangkan konsep sekolah sehat (Health Promoting School ), adalah sekolah yang telah melaksanakan UKS (Usaha Kesehatan Sekolah) dengan ciri-ciri melibatkan semua pihak yang berkitan dengan masalah kesehatan sekolah, menciptakan lingkungan yang sehat dan aman, memberikan pendidikan kesehatan, ada kebijakan dan upaya sekolah untuk mempromosikan kesehatan dan berperan aktif dalam meningkatkan kesehatan masyarakat.

Anak sekolah merupakan generasi penerus bangsa yang perlu dijaga, ditingkatkan dan dilindungi 
kesehatannya. Beberapa kegiatan peserta didik dalam menerapkan PHBS di sekolah antara lain mencuci tangan dengan sabun dan air bersih dengan menerapkan PHBS di sekolah maka peserta didik ikut berperan aktif dalam mewujudkan lingkungan sekolah yang sehat.

\section{METODE PENERAPAN}

1. Demonstrasi

Metoda yang demonstrasi yang digunakan dalam pengabdian ini dengan menggunakan model dimana model tersebut memberikan contoh langsung mempraktekkan Senam jantung sehat kepada Lansia, setelah didemontrasikan maka lansia dievaluasi untuk mempraktekkan langsung Senam jantung sehat.

2. Ceramah interaktif

Bentuk kegiatan dilakukan berupa penyuluhan dengan menggunakan alat bantu infocus dan leaflet serta brosur diberikan kepada lansia. Setelah diberikan pengetahuan tentang Senam jantung sehat maka akan dibuka forum diskusi tanya jawab.

\section{HASIL DAN PEMBAHASAN}

\section{A. Hasil Kegiatan}

Kegiatan

penyuluhan

tentang cara cuci tangan pakai sabun yang benar Berdasarkan tanya jawab dan pengamatan langsung selama kegiatan berlangsung, kegiatan pegabdian pada masyarakat ini memberikan hasil sebagai berikut :

1. Meningkatkan pengetahuan dan pemahaman anak usia dini yang sedang mengikuti penyuluhan tentang cara cuci tangan pakai sabun yang benar dilihat dari kemampuan anak yang bisa dalam menjawab pertanyaan yang diajukan oleh pemateri

2. Meningkatnya keterampilan anak usia dini dalam melakukan cara cuci tangan pakai sabun, sehingga dimungkinkan anak dapat melakukan cuci tangan pakai sabundengan benar.

3. Meningkatkan keterampilan anak usia dini dalam melakukan cara cuci tangan pakai sabun dengan benar, sehingga guru dan orang tua dapat terus memberikan pelatihan kepada anak yang lain cara melakukan cuci tangan pakai sabunyang benar. 

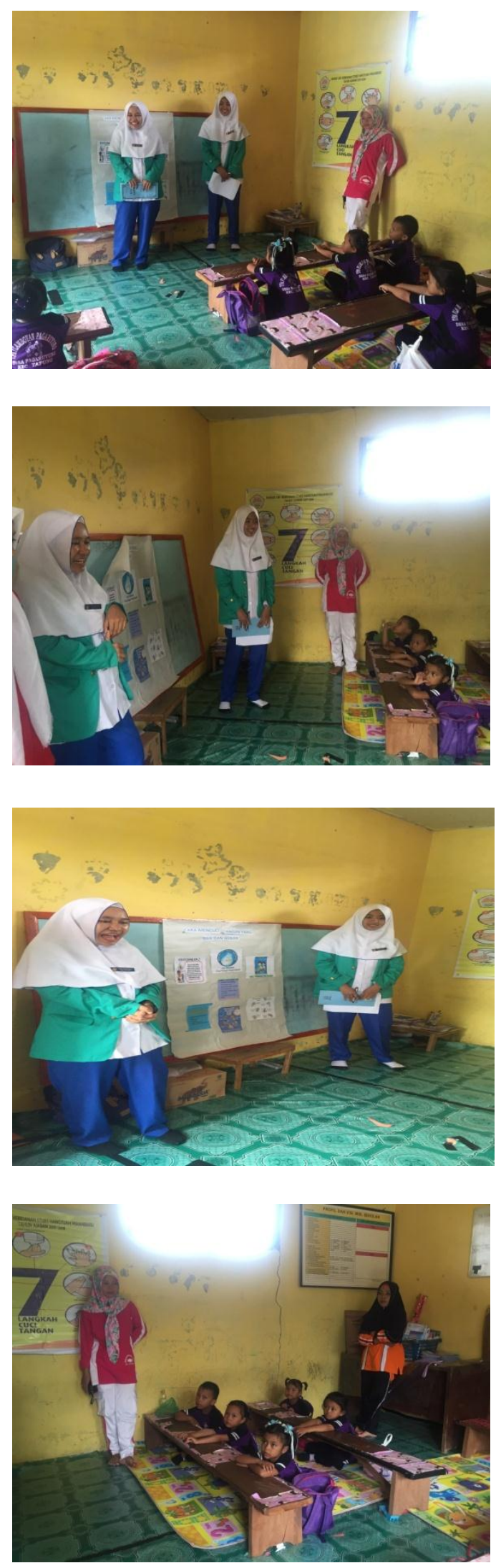
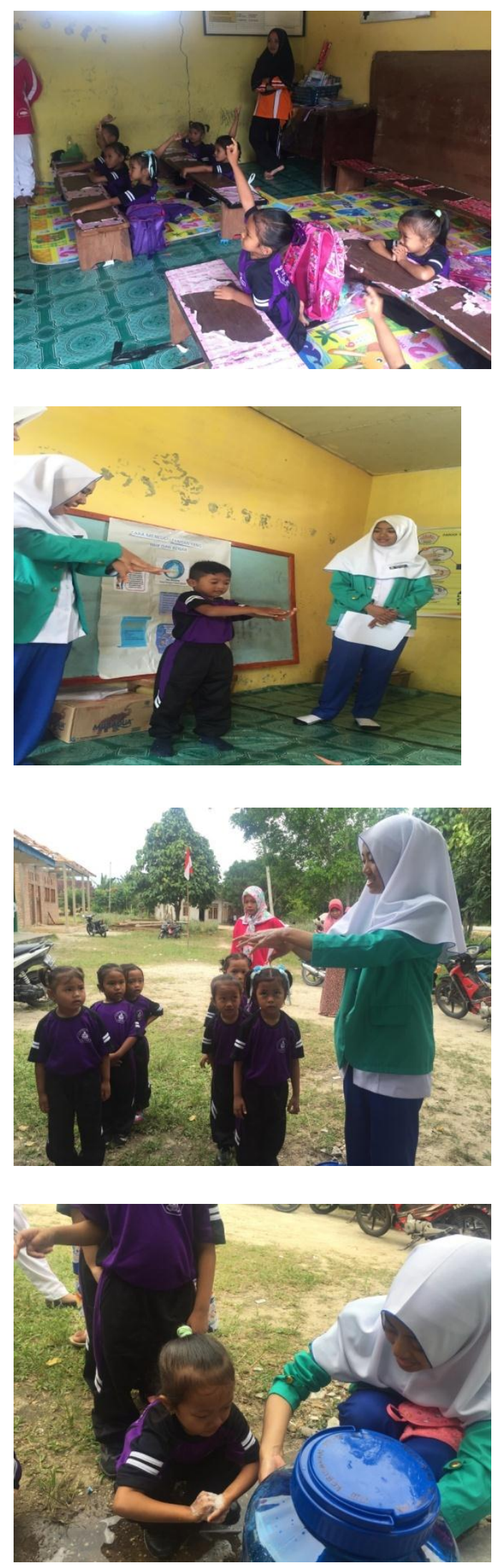

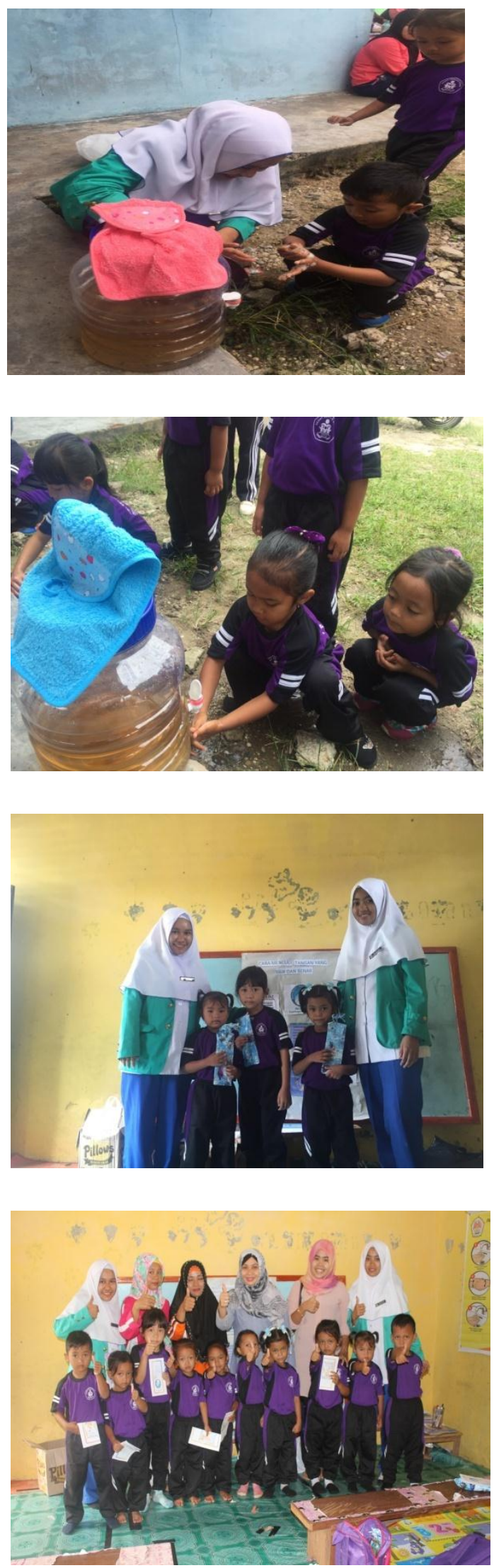

\section{PEMBAHASAN}

Anak usia dini dianjurkan melakukan cara cuci tangan pakai sabun dengan benar agar anak dapat hidup lebih sehat dan berkurangnya masalah-masalah yang timbul pada anak usia dini salah satu cara hidup sehat pada anak usia dini yaitu cara cuci tangan pakai sabun dengan benar ,Mencuci tangan adalah membersihkan tangan dari kotoran, mulai dari ujung jari hingga siku dan lengan atas dengan cara tertentu sesuai kebutuhan. Mencuci tangan pakai sabun mencegah terjadinya infeksi silang melalui tangan dan menjaga kebersihan individual. (kusyati,dkk, 2012)

\section{KESIMPULAN}

Dari kegiatan penyuluhan ini dapat disimpulkan bahwa

1. Antusias murid PAUD Flamboyan melakukan cara cuci tangan pakai sabun dengan baik dan benar telah meningkat.

2. Murid yang ada di PAUD Flamboyan mampu melakukan cuci tangan dengan baik dan benar. 
DAFTAR PUSTAKA

a. Kusyati,Eni.dkk.2014.Keterampila

$n$ dan Prosedur Laboratorium Keperawatan Dasar.Jakarta : EGC b. Asih,N.L.G.Y.1994.Seri Pedoman Praktis Prosedur Keperawatan Darurat. Jakarta : EGC 